
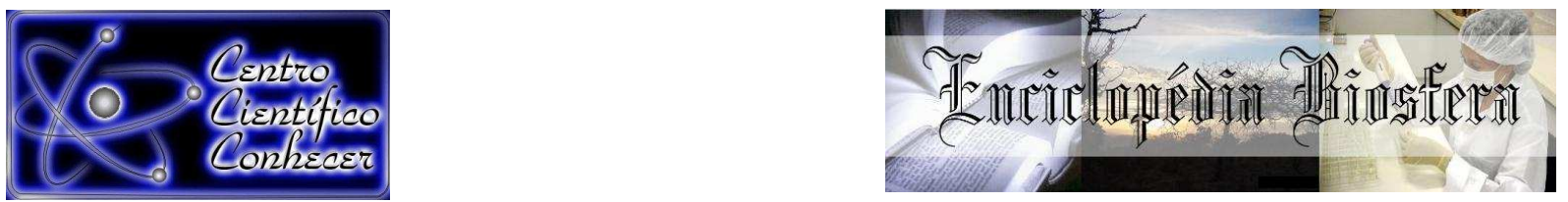

\title{
AJUSTES METODOLÓGICOS PARA A DETERMINAÇÃO DE UMIDADE EM SEMENTES DE ARROZ
}

Hélen Claudine Saliba Rodrigues ${ }^{1}$, Vanessa Nogueira Soares ${ }^{2}$, Ewerton Gewehr ${ }^{3^{*}}$, Ireni Leitzke Carvalho ${ }^{3}$, Géri Eduardo Meneghello ${ }^{4}$

${ }^{1}$ Doutora em Ciência e Tecnologia de Sementes, UFPel, Brasil

${ }^{2}$ Pós-doutoranda em Ciência e Tecnologia de Sementes, Universidade Federal de

Pelotas, Pelotas (UFPel), Brasil

${ }^{3}$ Doutorando em Ciência e Tecnologia de Sementes, UFPel, Brasil

*ewertongewehr@hotmail.com

${ }^{4}$ Pesquisador, Doutor em Ciência e Tecnologia de Sementes, UFPel, Brasil

Recebido em: 08/09/2015 - Aprovado em: 14/11/2015 - Publicado em: 01/12/2015 DOI: http://dx.doi.org/10.18677/Enciclopedia_Biosfera_2015_071

O objetivo do estudo foi determinar o teor de água em sementes de arroz com amostras menores do que o recomendado pelas Regras para Análise de Sementes (RAS). Utilizaram-se amostras de sementes de arroz com teor de água aproximado de 12, $15 \mathrm{e}$ $18 \%$. Foram pesadas duas subamostras de arroz com 1;2; 3 e 4,5 gramas (g) para cada umidade em estudo, as quais submetidas a determinação de umidade pelo método de estufa $105 \pm 3^{\circ} \mathrm{C}$ por 24 horas. Os resultados do grau de umidade das sementes foram obtidos pelo cálculo de umidade padrão e comparados com o limite máximo de tolerância para determinação do grau de umidade estabelecidos pelas RAS para sementes de grandes culturas. As amostras de arroz com 2; 3 e 4,5 gramas de sementes situaram-se dentro do limite máximo de tolerância para os teores de água avaliados. A determinação do teor de água em sementes de arroz com umidades de 12 , 15 e $18 \%$ pode ser feita com 2 e 3 g pelo método de estufa a $105 \pm 3{ }^{\circ} \mathrm{C}$ por 24 horas, não diferindo dos resultados obtidos com 4,5 g de sementes.

PALAVRAS-CHAVE: método de estufa, Oryza sativa, padrão de tolerância, teor de água.

\section{METHODOLOGICAL ADJUSTMENT FOR MOISTURE DETERMINATION IN RICE SEEDS}

\begin{abstract}
This work aimed was measure the moisture content in smaller samples of rice seeds than recommended in Rules for testing seeds. Rice seeds samples with 12, 15 and 18, and of moisture were weighed in two sub-samples of $1 ; 2 ; 3$ and 4.5 grams $(\mathrm{g})$. The samples were placed in oven-dry to $105^{\circ} \mathrm{C}$ for 24 hours. The results obtained by the
\end{abstract}


standard calculus of moisture were compared with maximum limits of tolerance established by the Rules for testing seeds for moisture content determination in field crops. The rice seeds samples with 2; 3 and $4.5 \mathrm{~g}$ remained within of tolerance standard limit for all evaluated moistures. The water content can be estimated with 2 and $3 \mathrm{~g}$ of seeds to 12,15 and $18 \%$ moisture by the oven-drying method for 24 hours, not differing of $4.5 \mathrm{~g}$ seeds.

KEYWORDS: oven-drying method, Oryza sativa, tolerance standard, water content.

\section{INTRODUÇÃO}

Os procedimentos para a execução do teste de determinação de umidade descritos nas Regras para Análise de Sementes - RAS, indicam que sejam utilizadas $4,5 \pm 0,5 \mathrm{~g}$ para a determinação do teor de água em sementes expostas à temperatura de $105 \pm 3 \stackrel{\circ}{\circ}$ por 24 horas. Apesar de estar prescrita nas RAS a amplitude de tolerância máxima de 0,5 a $0,9 \%$ para as diferenças entre duas subamostras de trabalho (repetições) de sementes de espécies palhentas, como arroz, trigo e milho (BRASIL, 2009), os resultados de uma mesma determinação são, geralmente, discrepantes, cujas diferenças ultrapassam esses limites.

A determinação de umidade para sementes de grandes culturas e de outras espécies está entre os parâmetros mais comuns utilizados em rotina de laboratório (AMOEDO \& MURADIAN, 2002) por ser um método simples e de fácil execução (ILELEJI, K.E. et al., 2010), que se baseia na perda de água quando estas são secadas em estufa, onde a umidade é calculada pela diferença de peso inicial e final das amostras (VUATAZ et al., 2010).

O teor de água em sementes influencia tanto no armazenamento quanto na comercialização do produto (RASCHEN et al., 2014). Sementes armazenadas em determinadas condições ambientais de umidade e de temperatura, favorecem a propagação de fungos e a produção de micotoxinas, que são prejudiciais à saúde (MILLER, 1995) e pode prejudicar a conservação das sementes, prejudicando sua germinação e vigor ao longo do tempo.

A aplicação de calor pelo método de estufa à $105^{\circ} \mathrm{C}$, possibilita que a água contida nas sementes seja expelida em forma de vapor, ao mesmo tempo que são minimizadas a oxidação, a decomposição e a perda de outras substâncias voláteis durante a operação; a redução do peso reflete a perda de água das sementes e, baseado neste princípio, as pesagens realizadas antes e após a secagem fornecem os dados para o cálculo do grau de umidade (BRASIL, 2009).

O teor de água interfere no valor econômico dos grãos e sementes, pois estes são comercializados por peso (BARROS \& SCHUCH, 2010). A redução do peso de amostras de sementes utilizadas na determinação de umidade pode ser um parâmetro importante para avaliar a máxima qualidade de sementes e indicar o momento ideal da colheita, já que nem todas as sementes atingem o ponto de maturação fisiológica ao mesmo tempo no campo. Além disso, o controle do grau de umidade tem grande importância na colheita e no beneficiamento, na conservação do poder germinativo e do vigor durante o armazenamento, na escolha do tipo de embalagem, no controle de insetos e de microrganismos e do peso durante a comercialização. No entanto, em algumas situações, os produtores podem não dispor de tal quantidade de sementes

ENCICLOPÉDIA BIOSFERA, Centro Científico Conhecer - Goiânia, v.11 n.22; p.70 2015 
para execução dos testes de umidade durante estas etapas, o que torna importante pesquisar a possibilidade de determinar o teor de água em sementes de arroz utilizando amostras menores que permaneçam dentro do limite de tolerância permitido para esta espécie.

\section{MATERIAL E MÉTODOS}

A pesquisa foi realizada no laboratório didático de Análises de Sementes "Flávio Farias Rocha", Universidade Federal de Pelotas, Pelotas - RS. As amostras de trabalho foram constituídas de semente inteiras de arroz da cultivar IRGA 424, com teor de umidade aproximado de $12 \%, 15 \%$ e $18 \%$. Para as pesagens realizou-se a présecagem de recipientes de metal de $0,5 \mathrm{~mm}$ de espessura que foram colocados por 30 minutos em estufa à $105^{\circ} \mathrm{C}$ antes da realização do teste e após resfriado em dessecador contendo sílica gel. As sementes úmidas foram pesadas em balança de $0,001 \mathrm{~g}$ de precisão para cada umidade em estudo, utilizando quatro subamostras com $1 ; 2 ; 3$ e 4,5 g. Em seguida, as sementes em seus respectivos recipientes foram acondicionadas à secagem em estufa a $105 \pm 3^{\circ} \mathrm{C}$ por 24 horas. Após este período, os recipientes contendo as sementes secas foram retirados do interior da estufa e permaneceram em dessecador até seu resfriamento por aproximadamente 30 minutos, até que os recipientes entrassem em equilíbrio com a temperatura ambiente. As sementes secas foram pesadas em balança de $0,001 \mathrm{~g}$ de precisão, obtendo-se os resultados finais. O grau de umidade foi calculado com base no peso úmido pelo cálculo de umidade padrão, seguido de comparação com o limite máximo de tolerância para determinação do grau de umidade de sementes de grandes culturas (Tabela 1), ambos estabelecidos pelas RAS (BRASIL, 2009).

As percentagens de umidade das sementes foram calculadas, conforme a fórmula descrita nas Regras de Análises de Sementes (BRASIL, 2009):

Em que:

$$
\% \text { de Umidade }(\mathrm{U})=\frac{100(\mathrm{P}-\mathrm{p})}{\mathrm{P}-\mathrm{t}}
$$

$\mathrm{P}=$ peso inicial, peso do recipiente e sua tampa mais o peso da semente úmida;

$p=$ peso final, peso do recipiente e sua tampa mais o peso da semente seca;

$\mathrm{t}=$ tara, peso do recipiente com sua tampa.

TABELA 1 Limites de tolerância para as diferenças entre a determinação de umidade na estufa em sementes de arroz (palhentas).

Média da determinação de umidade na estufa Tolerância

$\begin{array}{ll}<10,9 \% & 0,5 \\ 11-12,9 \% & 0,6 \\ 13-14,9 \% & 0,7 \\ 15-16,9 \% & 0,8 \\ 17-18,0 \% & 0,9\end{array}$


* Adaptado tabela 7.2 (BRASIL, 2009).

\section{RESULTADOS E DISCUSSÃO}

$\mathrm{Na}$ Tabela 2 são apresentados os resultados dos teores de umidade medidos pelo método de estufa a $105 \pm 3^{\circ} \mathrm{C}$. As amostras de arroz com 2; 3 e 4,5 gramas de sementes situaram-se dentro do limite máximo de tolerância para teores de umidade avaliados que foram de 12, 15 e $18 \%$. De acordo com os resultados da Tabela 2, foi observado que quanto menor a quantidade de sementes em pesos utilizadas na determinação de umidade, maior foi a diferença constatada entre o peso padrão $(4,5 \mathrm{~g})$ recomendado pelas Regras para Análises de sementes (RAS) e as quantidades de $1 \mathrm{~g}$, $2 \mathrm{~g}$ e $3 \mathrm{~g}$ de sementes de arroz utilizados para determinar o teor de água das mesmas, independente do percentual de umidade inicial testado. As quantidades de 1, 2 e $3 \mathrm{~g}$ de sementes não estão descritas nas Regras para Análises de Sementes (BRASIL, 2009) para a determinação de umidade. Contudo, as quantidades de sementes utilizadas neste trabalho não interferiram nos resultados e ficaram dentro dos limites padrões de tolerância (Tabela 1). Conforme BRASIL (2009), para o teste de umidade é recomendável utilizar cerca de $4,5 \pm 0,5 \mathrm{~g}$ ou $10,0 \pm 1,0 \mathrm{~g}$ de sementes dependendo da dimensão do recipiente. Entretanto, muitas vezes, não se dispõem de uma amostra em quantidade suficiente de sementes para determinação do teor de água, o que remete à necessidade de pesquisas com quantidades menores de sementes do que o recomendado pelas RAS.

Para a umidade inicial de $12 \%$, verificou-se que a determinação de umidade em estufa com $1 \mathrm{~g}$ de sementes de arroz ultrapassou os limites de tolerância permitidos de $0,6 \%$, para sementes de arroz ou sementes palhentas com umidade inicial na faixa de 11 a 12,9 \% (Tabela 1). CAMPOS \& TILLMANN (1996), trabalhando com determinação de umidade em sementes de arroz, trigo, soja e cebola pelo método de estufa à $105^{\circ} \mathrm{C}$, constataram para sementes de soja com umidades iniciais de 10,5 e 18,0\%, cebola; 11,$0 ; 14,0$ e $18,0 \%$, milho; 13,$0 ; 14,0$ e $19 \%$, trigo; 12,$0 ; 14,5$ e $18,0 \%$ e arroz $12,0 \%$, $14,5 \%$ e $18 \%$ que ocorreram diferenças na determinação de umidade de todas estas espécies ao utilizar 4,5 a $5 \mathrm{~g}$ de sementes. Para arroz e trigo foram observados menores teores de água para todos os níveis iniciais de umidade ao utilizar $5 \mathrm{~g}$ de sementes. De acordo com DIGNART et al. (2000), a determinação de umidade em sementes inteiras de bartimão e jatobá do cerrado pelo método de estufa e outros métodos utilizados, não se ajustaram aos limites de tolerância exigidos pelas RAS, no que se refere à variação entre repetições ao utilizar 4,5 a $5 \mathrm{~g}$ de sementes. Desse modo, pode-se inferir que a quantidade de sementes no teste de determinação de umidade tem resultados variados dependendo dos níveis de umidade iniciais ajustados para sementes de arroz. 
TABELA 2 Valores médios dos teores de umidade medidos pelo método da estufa a $105^{\circ} \mathrm{C}$ com subamostras de 1; $2 ; 3$ e 4,5 g de sementes de arroz.

\begin{tabular}{|c|c|c|c|}
\hline Amostra & Peso da amostra (g) & Umidade estufa (\%) & $\begin{array}{l}\text { Diferença em } \\
\text { relação } \\
\text { metodologia padrão } \\
\text { (ponto percentual) }\end{array}$ \\
\hline \multirow{4}{*}{ Um } & 1 & 12,9 & $0,8^{*}$ \\
\hline & 2 & 12,2 & $0,1^{\mathrm{ns}}$ \\
\hline & 3 & 12,0 & $0,1^{\mathrm{ns}}$ \\
\hline & 4,5 & $12,1^{1}$ & \\
\hline \multirow{4}{*}{ Dois } & 1 & 13,2 & 1,5 \\
\hline & 2 & 15,2 & $0,5^{\mathrm{ns}}$ \\
\hline & 3 & 15,1 & $0,4^{\mathrm{ns}}$ \\
\hline & 4,5 & $14,7^{1}$ & \\
\hline \multirow{4}{*}{ Três } & 1 & 17,2 & $0,7^{\mathrm{ns}}$ \\
\hline & 2 & 17,8 & $0,1^{\mathrm{ns}}$ \\
\hline & 3 & 17,4 & $0,5^{\mathrm{ns}}$ \\
\hline & 4,5 & 17,91 & \\
\hline
\end{tabular}

1 Umidades obtidas com utilização de metodologia padrão. ${ }^{\text {ns }}$ Não significativo pela tabela de tolerância das Regras para Análise de Sementes. *Significativo pela tabela de tolerância das Regras para Análise de Sementes.

Para a umidade inicial de $15 \%$, os valores médios de determinação de umidade em estufa encontram-se na faixa de $15 \%$ a $16,9 \%$, com limite máximo de tolerância permitido de $0,8 \%$. No entanto, para esta umidade inicial testada, foi verificado comportamento similar a umidade de $12 \%$ para $1 \mathrm{~g}$ de sementes, onde os resultados percentuais do teor de água das sementes de arroz não se situaram dentro do limite de tolerância (Tabela 1). Por outro lado, ao utilizar 2 e $3 \mathrm{~g}$ de sementes de arroz no teste de determinação de umidade, os resultados do cálculo de umidade obtido para 15\%, mantiveram-se abaixo do percentual de tolerância de $0,8 \%$ aceitados pelas RAS (Tabela 1). Segundo, PESKE \& MENEGHELLO (2013) entende-se por limite um percentual ou quantidade acima ou abaixo da qual não se aceita as sementes para comercialização ao avaliar o teor de agua das mesmas durante um procedimento tecnológico (colheita, secagem, armazenamento, etc.). Se estes limites estiverem acima ou abaixo dos padrões estabelecidos por normas governamentais, estas sementes não serão colocadas para a comercialização. Os mesmos autores comentam que a 
determinação de umidade é um parâmetro que indica o controle interno de qualidade das sementes produzidas e a garantia da qualidade do produto disponível no mercado, os quais são aferidos por limites, tolerâncias e padrões no processo de produção e comércio de sementes.

Em contrapartida aos resultados encontrados para as umidades iniciais de $12 \% \mathrm{e}$ $15 \%$, foi possível utilizar $1 \mathrm{~g}$ de sementes na umidade inicial de $18 \%$ (Tabela 2 ) no teste de determinação de umidade para a espécie de arroz, estando de acordo aos limites de tolerância padrão (Tabela 1). Tal comportamento também foi constatado para 2 e $3 \mathrm{~g}$ de sementes utilizadas no teste comparado ao peso padrão de $4,5 \mathrm{~g}$ indicado pelo método oficial de determinação de umidade estabelecido pelas RAS. Em suma, todos os pesos utilizados na determinação de umidade em sementes de arroz, situaram-se dentro do percentual de tolerância para a umidade de $18 \%$, conforme comparados aos valores descritos nas Tabela 1 e 2 . Para a umidade inicial de $18 \%$, constatou uma menor diferença no percentual de tolerância entre 2 e $4,5 \mathrm{~g}$ e 1 e $3 \mathrm{~g}$ de sementes, apesar de todas as quantidades de sementes utilizadas em pesos, permanecerem dentro dos padrões de tolerância descritos pelas RAS (Tabela 1). LENZ et al. (2011) ao avaliarem o percentual de umidade em sementes de milho em diferentes estágios de maturação, constataram que as amostras de milho mais maduras apresentaram menor umidade do que as amostras mais jovens, ainda em fase de desenvolvimento, obtendo um controle mais eficaz durante o processo de produção de suas sementes.

UTINO \& PETERS (2006) comentaram que o controle do teor de água em sementes é de fundamental importância, principalmente na etapa de armazenamento após a colheita no campo, quando estas são levadas para a etapa de beneficiamento, ainda apresentam teor de umidade elevado, os quais não permitem que sejam armazenadas, pois se estas forem armazenadas com elevado teor de água, resultará no aquecimento na massa de grãos, por meio da fermentação e desenvolvimento de fungos, que irão comprometer a qualidade fisiológica das sementes.

PESKE \& MENEGHELLO (2013) relataram que o metabolismo das sementes é fortemente influenciado pelo seu grau de umidade e dependendo de seu percentual, é possível ter uma ideia do seu potencial de armazenamento ou se poderá desencadear o processo de germinação. Para isto, foi estabelecido como parâmetro para a comercialização de sementes de grandes culturas o percentual de $13 \%$ de umidade, ou seja, toda semente com mais de $13 \%$ terá seu peso ajustado para $13 \%$. Por outro lado, lotes de sementes com menos de $13 \%$, em geral não sofrem ajuste em seu peso; isto principalmente por possuírem um maior potencial de armazenamento.

\section{CONCLUSÃO}

Com base nos resultados encontrados neste experimento, a determinação do teor de água em sementes de arroz com umidades de 12, 15, e 18\% pode ser feita com 2 e $3 \mathrm{~g}$ pelo método de estufa a $105 \pm 3{ }^{\circ} \mathrm{C}$ por 24 horas, não diferindo dos resultados obtidos com $4,5 \mathrm{~g}$ de sementes.

\section{REFERÊNCIAS}

AMOEDO, L.H.G.; MURADIAN, L.B.A. Comparação de metodologias para a determinação de umidade em geléia real. Química Nova, v.25, p.676-679, 2002. 
http://www.scielo.br/pdf/qn/v25n4/10544.pdf. DOI: 10.1590/S0100-40422002000400024

BARROS, A. C. A.; SCHUCH, L. O. O momento de colher. SEED news, v. XIV, n.3, p. 24-29, 2010.

BRASIL. Ministério da Agricultura e Reforma Agrária. Regras para análise de sementes. Brasília, 365p, 2009.

CAMPOS, V. C.; TILLMANN, M. A. A. Comparação entre os métodos oficiais de estufa para determinação do grau de umidade de sementes. Revista Brasileira de Sementes, v.18, n.1, p.134-137. 1996.

DIGNART, S.; CAMARGO, I. P. DE; FERRONATO, A. Comparação entre os métodos para determinar o grau de umidade em sementes de jatobá-do-cerrado (Hymenaea stigonocarpa (hayne) mart.) e de barbatimão (Stryphnodendron adstringens (mart.) Cov.). Revista Brasileira de Sementes, v.22, n.2, p.300-303. 2000.

ILELEJI, K.E.; GARCIA, A. A.; KINGSLY, A. R.; CLEMENTSON, C. L. Comparison of standard moisture loss-on-drying methods for the determination of moisture content of corn distillers dried grains with solubles. Journal of AOAC Internacional, v.93, n.3, p.825-832,2010.

http://aoac.publisher.ingentaconnect.com/content/aoac/jaoac/2010/00000093/00000003/ art00013

LENZ, G. F.; SIMSEN, V. L.; DUARTE, R. A.; MARTIN, C. A.; \& MARINS. A. C. Determinação de umidade de milho utilizando o método estufa. In: Encontro de Divulgação Científica e Tecnológica Encontro de Divulgação Científica e Tecnológica, 3, 2011. Toledo. Anais...Universidade Federal do Paraná, 2011. Disponível em: http://www.utfpr.edu.br/toledo/estrutura-universitaria/diretorias/dirppg/anais-do-endictencontro-de-divulgacao-cientifica-e-tecnologica/anais-doiiiendict.pdf. Acesso em 02 de setembro de 2015.

MILLER, J.D. Fungi and mycotoxins in grain: implications for stored product research. Journal of Stored Products Research, v.31, p.l-16, 1995. http://wwwsciencedirect-com.ez66.periodicos.capes.gov.br/science/article/pii/0022474X9400039V DOI:10.1016/0022-474X(94)00039-V

PESKE, S. T.; MENEGHELLO, G. E. Limites, tolerâncias e padrões. SEEDS news, v. XVII, n.5, p.26-32, 2013.

RASCHEN, M. R.; LUCION, F.B.; CICHOSKI, A. J.; MENEZES, C. R.; WAGNER, R.; LOPES, E.J.; ZEPKA, L. Q.; BARIN, J. S. Determinação do teor de umidade em grãos empregando radiação micro-ondas. Revista Ciência Rural, v.44 n.5, 2014. http://www.scielo.br/pdf/cr/v44n5/a14714cr6846.pdf DOI: 10.1590/S010384782014000500026 
UTINO, S.; PETERS, V. Cultivo do Arroz de Terras Altas no Estado de Mato Grosso-Produção de Sementes. 2006. (Sistemas de Produção № 07). Disponível em: http://sistemasdeproducao.cnptia.embrapa.br/FontesHTML/Arroz/ArrozTerrasAltasMator osso/producao_sementes.htmhttp://sistemasdeproducao.cnptia.embrapa.br/FontesHTM L/Arroz/ArrozTerrasAltasMatoGrosso/producao_sementes.htm. Acesso em: 01 de setembro de 2015.

VUATAZ, G.; MEUNIER, V.; ANDRIEUX, J.C. TG-DTA approach for designing reference methods for moisture content determination in food powders. Food

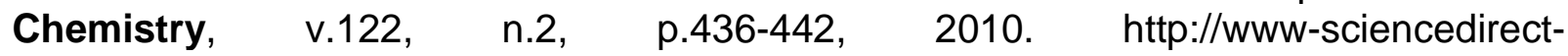
com.ez66.periodicos.capes.gov.br/science/article/pii/S0308814609007675

DOI:10.1016/j.foodchem.2009.05.066 